\title{
Exercise performance and gas exchange after bilateral video-assisted thoracoscopic lung volume reduction for severe emphysema
}

\author{
U. Stammberger*, K.E. Bloch**, R. Thurnheer**, R. Bingisser**, W. Weder*, E.W. Russi**
}

Exercise performance and gas exchange after bilateral video-assisted thoracoscopic lung volume reduction for severe emphysema. U. Stammberger, K.E. Bloch, R. Thurnheer, R. Bingisser, W. Weder, E.W. Russi. (CERS Journals Ltd 1998.

ABSTRACT: Lung volume reduction surgery (LVRS) improves dyspnoea and pulmonary function in selected patients with severe emphysema. The purpose of this study was to assess the effects of LVRS on exercise performance and gas exchange in relation to changes in pulmonary function.

In 40 patients $(63.2 \pm 1.4 \mathrm{yrs}$, mean $\pm \mathrm{sE})$ with severe emphysema (forced expiratory volume in one second $(\mathrm{FEV} 1) 29 \pm 1 \%$ predicted, residual volume/total lung capacity (RV/TLC) ratio: $0.63 \pm 0.01)$ we assessed dyspnoea, pulmonary function and exercise performance before and 3 months after bilateral video-assisted thoracoscopic LVRS.

The Medical Research Council dyspnoea score fell from 3.5 \pm 0.1 to $1.4 \pm 0.1(p<0.0005)$; FEV1 increased by $55 \pm 9 \%$ to $44 \pm 2 \%$ pred $(p<0.0005)$, RV/TLC decreased from $0.63 \pm$ 0.01 to $0.51 \pm 0.02(p<0.0005)$. The diffusing capacity remained unchanged. Maximal work load during bicycle ergometry increased from $34.3 \pm 2.0$ to $48.9 \pm 2.4 \mathrm{~W}$ (p< $0.0005)$, maximal oxygen uptake $\left(V^{i} O_{2}\right.$, max $)$ from $10.0 \pm 0.4$ to $12.8 \pm 0.3 \mathrm{~mL} \cdot \mathrm{kg}^{-1} \cdot \mathrm{min}^{-1}$ $(\mathrm{p}<0.0005)$. The increase in maximal ventilation during exercise $\left(V^{\prime} E, \max \right)$ from $29.5 \pm$ 1.5 to $38.6 \pm 1.8 \mathrm{~L}^{\prime} \mathrm{min}^{-1}(\mathrm{p}<0.0005)$ was associated with increases in tidal volumes at isowatt and maximal exercise while corresponding breathing frequencies remained unaltered. The increases in $V^{\prime} O_{2}$, max and $V^{\prime} E$,max correlated with the increases in FEV1 and the decreases in RV/TLC.

We conclude that the improvement in pulmonary hyperinflation and airflow obstruction after bilateral thoracoscopic lung volume reduction surgery may reduce ventilatory limitation, thereby increasing exercise capacity. Eur Respir J 1998; 12: 785-792.
*Dept of Surgery and Pulmonary Division, **Dept of Internal Medicine, University Hospital, Zürich, Switzerland.

Correspondence: E.W. Russi

Pulmonary Division

Dept of Internal Medicine

University Hospital

Rämistr. 100

CH-8091 Zürich

Switzerland

Fax: 4112554451

Keywords: Emphysema

exercise

gas exchange

lung volume reduction surgery

thoracoscopy

Received: November 201997

Accepted after revision May 251998

This study was supported by grants from the Swiss National Science Foundation and the Zurich Lung League.
Lung volume reduction surgery (LVRS) has become a novel palliative therapeutic option for a subgroup of patients who are impaired in their daily activity by dyspnoea due to pulmonary emphysema with severe hyperinflation. The surgical principle is based on the concept of BRANTIGAN et al. [1] which was revived by COOPER et al. [2]. From the published experience of several groups it has become obvious that bilateral resection results in greater improvement of pulmonary function [2-8] than unilateral resection [9-11], and that stapled resection causes larger changes than laser resection [9].

Patients with moderate to severe chronic obstructive pulmonary disease are primarily limited in their exercise performance by a decrease in ventilatory capacity due to abnormal pulmonary mechanics [12]. Studies in a relatively small number of patients after bilateral LVRS by median sternotomy [13] and after unilateral video-assisted thoracoscopic LVRS [14] have suggested that a decrease in bronchial obstruction and reduction in pulmonary hyperinflation enable the patient to achieve a higher maximal minute ventilation after LVRS and therefore contribute to reduce the patients' exercise limitation.
The goal of this study was to investigate exercise performance and gas exchange in patients with severe pulmonary emphysema before and after bilateral video-assisted thoracoscopic LVRS in relation to changes in pulmonary function.

\section{Patients and methods}

\section{Patients}

We studied 40 consecutive patients with severe pulmonary emphysema, selected for bilateral LVRS by videoassisted thoracoscopy according to previously established criteria [15]. These included the following (incomplete list): advanced emphysema with dyspnoea at rest or on minimal exertion, a forced expiratory volume in one second (FEV 1 ) $<35 \%$ predicted, a total lung capacity (TLC) of $>130 \%$ predicted and no significant coronary artery disease [16]. The mean ( \pm SEM) age of the 27 males and 13 females was $63.2 \pm 1.4$ yrs (range $42-78 \mathrm{yrs}$ ). Their mean body mass index (BMI) was $21.8 \pm 0.5 \mathrm{~kg} \cdot \mathrm{m}^{-2}$ (range: $15.2-30.9$ ). All 
were former smokers, three had homozygous $\alpha$-1-antitrypsin deficiency (ZZ). They were on a regular treatment consisting of inhalations of $\beta$-adrenergic agents and topical corticosteroids. Every patient had received one or several courses of systemic corticosteroids in the past without functional benefit. Patients did not participate in a systematic pre- or postoperative rehabilitation programme.

The following measurements were carried out within 2 weeks before and 3 months after surgery.

\section{Dyspnoea}

Dyspnoea during daily activity was rated on a scale from 0 to 4 (with increasing severity) according to the American Thoracic Society (ATS) Modified Medical Research council (MRC) score [17].

\section{Pulmonary function}

Tests were performed $10 \mathrm{~min}$ after inhalation of two puffs of salbutamol. Spirometry and measurements of thoracic gas volumes were performed with a mass flow meter and a body plethysmograph (6200 Autobox ${ }^{\circledR}$, Sensor Medics, Yorba Linda, CA, USA). Diffusing capacity for carbon monoxide $(D \mathrm{~L}, \mathrm{CO})$ was measured with an infrared analyser (Model 66200® SenorMedics, Yorba Linda, CA, USA) which uses methane as inert tracer gas. Criteria for acceptability and reproducibility and predicted normal values were according to the European Community of Coal and Steel (ECCS) [18].

\section{Six minute walking distance}

The patients walked in the same hospital hallway without oxygen supplementation encouraged by a technician.

\section{Arterial blood gases}

Arterial blood gases were sampled by puncturing the radial artery of the patient sitting on the bicycle at rest and immediately before the patient stopped to exercise (i.e. at maximal exercise) and analysed by an automated blood gas measurement system (AVL 995-S, AVL® Medical Instruments, Schaffhausen, Switzerland).

\section{Cardiopulmonary exercise tests}

These were performed on an electronically braked cycle ergometer (Bosch Medicare, Zurich, Switzerland) according to a progressive ramp protocol with a slope of $5 \mathrm{~W}$. $\mathrm{min}^{-1}$ to exhaustion. Expiratory ventilation, oxygen uptake and carbon dioxide output were measured breath-by-breath and averaged over successive $15 \mathrm{~s}$ intervals by a computerized exercise and metabolic measurement system (VMax, SensorMedics). Heart rate and rhythm were monitored by a three lead electrocardiogram. Arterial blood gases were analysed by an automated blood gas measurement system (AVL 995-S; AVL® Medical Instruments). Maximal values $(\max )$ for minute ventilation $\left(V^{\prime} \mathrm{E}, \max \right)$, respiratory frequency ( $f$ Rmax $)$, tidal volume $(V T, \max )$, oxygen uptake $\left(V^{\prime} \mathrm{O}_{2}\right.$, max), carbon dioxide consumption $\left(V^{\prime} \mathrm{CO}_{2}\right.$, max $)$, respiratory exchange ratio $(\mathrm{RQmax})$, heart rate (HRmax) and maximal work rate $(W \max )$ were taken as the values corresponding to the $15 \mathrm{~s}$ interval with the highest oxygen uptake $\left(V^{\prime} \mathrm{O}_{2}\right.$, $\max )$. The dead space to tidal volume ratio $(V \mathrm{D} / V \mathrm{~T})$ was calculated at rest and at maximal exercise according to the modified Bohr equation:

$$
V \mathrm{D} / V \mathrm{~T}=\left(\left(P \mathrm{a}, \mathrm{CO}_{2}-P \mathrm{E}, \mathrm{CO}_{2}\right) / P \mathrm{a}, \mathrm{CO}_{2}\right)-0.115 / V \mathrm{~T}
$$

Where $P \mathrm{a}, \mathrm{CO}_{2}$ is arterial carbon dioxide tension, $P \mathrm{E}, \mathrm{CO}_{2}$ is mixed expired carbon dioxide, and $0.115 \mathrm{~L}$ is apparatus dead space. External work efficiency $\left(\Delta V^{\prime} \mathrm{O}_{2} / \Delta W\right)$ was computed by performing a linear regression of $V^{\prime} \mathrm{O}_{2}$ versus work rate at ranges below the anaerobic threshold or up to $75 \% V^{\prime} \mathrm{O}_{2}$,max. Breathing reserve was calculated as $\left((\mathrm{FEV} 1 \times 37.5)-V^{\prime} \mathrm{E}, \max \right)$ and expressed in $\mathrm{L} \cdot \mathrm{min}^{-1}$ and as percentage of $(\mathrm{FEV} 1 \times 37.5)$. Heart rate reserve was defined as ((215-age)-HRmax) and expressed in beats. min $^{-1}$. The alveolar-arterial partial pressure gradient for oxygen $\left(\mathrm{PA}-\mathrm{a}, \mathrm{O}_{2}\right)$ was calculated from the alveolar gas equation as:

$$
P \mathrm{~A}-\mathrm{a}, \mathrm{O}_{2}=F \mathrm{I}, \mathrm{O}_{2}\left(P \mathrm{~B}-P \mathrm{H}_{2} \mathrm{O}\right)-\frac{P \mathrm{a}, \mathrm{CO}_{2}}{\mathrm{RER}}\left(1+F \mathrm{I}, \mathrm{O}_{2}(1-R)\right)
$$

using measured values for $P_{\mathrm{a}}, \mathrm{CO}_{2}$, barometric pressure $(P \mathrm{~B})$, and respiratory exchange ratio (RER). Partial pressure of water $\left(\mathrm{PH}_{2} \mathrm{O}\right)$ was taken as $6.3 \mathrm{kPa}(47 \mathrm{mmHg})$, and inspired oxygen fraction $\left(F \mathrm{I}, \mathrm{O}_{2}\right)$ as 0.21 .

\section{Surgical technique}

LVRS was performed bilaterally by video-assisted thoracoscopy as described previously $[4,5]$. Resection was aimed at the most destroyed areas of the lungs previously identified by computed tomography (CT) of the chest [19] and perfusion scintigraphy. Excised pieces of lung had an estimated cumulative volume of approximately 20-30\% of the lung volume. The staplers were not buttressed. At the end of the procedure, drainage tubes were placed bilaterally into the pleural cavity and connected to suction of $10-20 \mathrm{cmH}_{2} \mathrm{O}$ or Heimlich valves. Extubation was performed in the theatre immediately after the operation. Patients stayed in the hospital for a median duration of 13 days, ranging 5-51 days. Median chest tube drainage time was 9 days (3-48 days).

\section{Statistics}

Values are presented as means \pm SEM. Preoperative parameters of pulmonary function and maximal exercise performance were compared with corresponding postoperative values by paired t-tests for dependent samples. Submaximal exercise performance at isowatt work rate ranges was analysed by computing individual means of cardiorespiratory variables over successive $5-\mathrm{W}$ work rate ranges. The effects of LVRS and of work loads on group means were assessed by multivariate analysis of variance followed by the Newman-Keuls multiple comparisons procedure, where appropriate. The association between preoperative baseline parameters and changes in variables of exercise performance were quantified by the Pearson product moment coefficients of correlation. A probability of $p<0.05$ was considered as significant. 


\section{Results}

\section{Dyspnoea and pulmonary function}

According to the selection criteria, preoperative patients suffered from heavy dyspnoea related to severe airflow obstruction and hyperinflation (table 1). Three months after LVRS, dyspnoea had improved, as demonstrated by a decrease in MRC dyspnoea score of 2-4 points in all patients. Obstructions to airflow and hyperinflation were significantly reduced. The latter became apparent due to a marked reduction in residual volume (RV), TLC and their ratio, and by an increase in vital capacity (table 1).

\section{Gas exchange at rest}

Preoperatively, six patients qualified for long-term oxygen therapy (arterial oxygen tension $\left.\mathrm{Pa}_{\mathrm{a}} \mathrm{O}_{2}\right)$ $\partial 7.3 \mathrm{kPa}(55$ $\mathrm{mmHg}$ ) [20], but none of the patients had a $\mathrm{Pa}_{2} \mathrm{CO}_{2}>6.4 \mathrm{kPa}$ (48 mmHg). Postoperatively, the $P_{\mathrm{a}}, \mathrm{O}_{2}$ at rest had increased, whereas $\mathrm{Pa}, \mathrm{CO}_{2}$ had decreased slightly (table 1). $\mathrm{PA}-\mathrm{a}, \mathrm{O}_{2}$ remained unchanged. Furthermore, we did not observe significant changes in $D \mathrm{~L}, \mathrm{CO}$.

\section{Exercise performance}

Preoperative assessment revealed a severe impairment in exercise performance with a mean 6 min walking distance of $279 \pm 14 \mathrm{~m}$ (range 45-450) and a mean $V^{\prime} \mathrm{O}_{2}$, max of $10.0 \pm 0.4$ (range $6.5-15.8$ ) $\mathrm{mL} \cdot \mathrm{kg}^{-1} \cdot \mathrm{min}^{-1}$ (table 2). Since breathing reserve was $<15 \mathrm{~L} \cdot \mathrm{min}^{-1}$ in all patients, and even less than zero in some, while heart rate reserve was considerable, their exercise performance was restrained by ventilatory limitation at a very low work rate (table 2). Consistent with these findings, breathing pattern at maximal exercise was rapid and shallow with a low $V \mathrm{~T}$ and $V \mathrm{~T}$ to inspiratory vital capacity (VT/IVC) ratio (fig. 1). Due to increased dead space ventilation, the ventilatory equivalent for $\mathrm{CO}_{2}\left(V^{\prime} \mathrm{E} / V^{\prime} \mathrm{CO}_{2}\right)$ was high.

After surgery, the mean 6 min walking distance was significantly improved and 35 of the 40 patients increased maximal performance during bicycle exercise (table 2). $V^{\prime} \mathrm{O}_{2}$, max increased by a mean of $2.8 \mathrm{~mL} \cdot \mathrm{kg}^{-1} \cdot \mathrm{min}^{-1}$ in $37 \mathrm{pa}-$ tients, in one of them up to $6.8 \mathrm{~mL} \cdot \mathrm{kg}^{-1} \cdot \mathrm{min}^{-1}$, but decreased between 0.7 and $1.2 \mathrm{~mL} \cdot \mathrm{kg}^{-1} \cdot \mathrm{min}^{-1}$ in three patients. The postoperative gain in maximal performance was associated with a change in breathing pattern towards slower and deeper breathing at corresponding work rates and levels of ventilation (fig. 1). The reductions of airflow obstruction and hyperinflation (table 1) were accompanied by an increase in $V^{\prime} \mathrm{E}$, max (table 2).

The individual changes in $V^{\prime} \mathrm{E}, \max$ and $V^{\prime} \mathrm{O}_{2}$, max were significantly correlated with the changes in FEV1 $(\mathrm{R}=0.72$, $\mathrm{p}<0.05$, and $\mathrm{R}=0.53, \mathrm{p}<0.05$, respectively) and the changes in $\mathrm{RV} / \mathrm{TLC}(\mathrm{R}=-0.60, \mathrm{p}<0.05$, and $\mathrm{R}=-0.49, \mathrm{p}<0.05$, respectively). As the increase in breathing reserve was only moderate, the patients' maximal exercise performance remained limited by the reduced ventilatory capacity (table 2). Elimination of $\mathrm{CO}_{2}$ was improved due to a reduction in dead space ventilation at maximal exercise as evidenced by reductions in $V \mathrm{D} / V \mathrm{~T}, V^{\prime} \mathrm{E} / V^{\prime} \mathrm{CO}_{2}$ and a slight but statistically significant reduction in $P \mathrm{a}, \mathrm{CO}_{2}$ despite an even higher workload. The heart rate reserve remained unchanged, but the oxygen pulse at maximal exercise $\left(V^{\prime} \mathrm{O}_{2}, \max / \mathrm{HR} \max \right)$ increased (table 2).

Before surgery, $\mathrm{Pa}, \mathrm{O}_{2}$ during maximal exercise decreased by a mean of $1.05 \pm 0.17 \mathrm{kPa}(7.9 \pm 1.3 \mathrm{mmHg})(12 \%$; $\mathrm{p}<0.0005$ ) from baseline, resulting in a exercise $\mathrm{Pa}, \mathrm{O}_{2}$ below $8.0 \mathrm{kPa}(60 \mathrm{mmHg})$ in 24 of 39 patients. After LVRS, the mean exercise-induced drop was $1.48 \pm 0.17 \mathrm{kPa}(11.1 \pm$ $1.3 \mathrm{mmHg}$ ) at a higher level of maximal workload (table 2). After LVRS, $\mathrm{Pa}, \mathrm{O}_{2}$ in 18 of 39 patients still dropped below $8.0 \mathrm{kPa}(60 \mathrm{mmHg})$ during exercise, and the increase in

Table 1. - Dyspnoea, lung volumes and gas exchange at rest (mean values \pm SEM)

\begin{tabular}{|c|c|c|c|c|c|}
\hline \multirow{2}{*}{\multicolumn{2}{|c|}{ Dyspnoea score }} & Before surgery & After surgery & $\Delta$ Postop-Preop & $\Delta$ Postop-Preop $\%$ \\
\hline & & $3.5 \pm 0.1$ & $1.4 \pm 0.1$ & $-2.0 \pm 0.2^{+}$ & \\
\hline FVC & $\mathrm{L}$ & $2.48 \pm 0.12$ & $\begin{array}{l}3.40 \pm 0.16 \\
96+2\end{array}$ & $0.92 \pm 0.12+$ & $42 \pm 7+$ \\
\hline FEV1 & $\mathrm{L}$ & $0.82 \pm 0.04$ & $1.25 \pm 0.09$ & $0.44 \pm 0.07+$ & $55 \pm 9+$ \\
\hline IVC & $\begin{array}{l}\% \text { pred } \\
\mathrm{L} \\
\% \text { pred }\end{array}$ & $\begin{array}{c}29 \pm 1 \\
3.15 \pm 0.14 \\
86 \pm 3\end{array}$ & $\begin{array}{c}44 \pm 2 \\
3.77 \pm 0.17 \\
102 \pm 2\end{array}$ & $\begin{array}{c}15 \pm 2+ \\
0.62 \pm 0.12^{+} \\
16 \pm 3^{+}\end{array}$ & $23 \pm 5^{+}$ \\
\hline TLC & $\begin{array}{l}\mathrm{L} \\
\% \text { pred }\end{array}$ & $\begin{array}{l}8.45 \pm 0.23 \\
139 \pm 3\end{array}$ & $\begin{array}{l}7.74 \pm 0.21 \\
127 \pm 3\end{array}$ & $\begin{array}{c}-0.69 \pm 0.11^{+} \\
-11 \pm 2^{+}\end{array}$ & $-8 \pm 1+$ \\
\hline RV & $\begin{array}{l}\mathrm{L} \\
\% \text { pred }\end{array}$ & $\begin{array}{l}5.32 \pm 0.16 \\
239 \pm 8\end{array}$ & $\begin{array}{l}3.96 \pm 0.16 \\
178 \pm 8\end{array}$ & $\begin{array}{c}-1.34 \pm 0.16^{+} \\
-60 \pm 7^{+}\end{array}$ & $-25 \pm 3^{+}$ \\
\hline RV/TLC & & $0.63 \pm 0.01$ & $0.51 \pm 0.02$ & $-0.12 \pm 0.02+$ & \\
\hline FRC & $\begin{array}{l}\mathrm{L} \\
\% \text { pred }\end{array}$ & $\begin{array}{c}6.42 \pm 0.19 \\
198 \pm 5\end{array}$ & $\begin{array}{c}5.29 \pm 0.16 \\
164 \pm 5\end{array}$ & $\begin{array}{c}-1.11 \pm 0.14^{+} \\
-34 \pm 4^{+}\end{array}$ & $-17 \pm 2+$ \\
\hline$D \mathrm{~L}, \mathrm{CO}$ & $\begin{array}{l}\mathrm{mL} \cdot \mathrm{kPa}^{-1} \cdot \mathrm{min}^{-1} \\
\% \text { pred }\end{array}$ & $\begin{array}{c}11.2 \pm 0.6 \\
44 \pm 2\end{array}$ & $\begin{array}{c}11.6 \pm 0.5 \\
46 \pm 2\end{array}$ & $\begin{array}{c}0.3 \pm 0.6 \\
1 \pm 2\end{array}$ & \\
\hline $\mathrm{pH}$ & & $7.41 \pm 0.01$ & $7.41 \pm 0.00$ & $-0.18 \pm 0.18$ & \\
\hline$P \mathrm{a}, \mathrm{CO}_{2}$ & $\mathrm{mmHg}$ & $38 \pm 1$ & $35 \pm 1$ & $-3 \pm 1+$ & \\
\hline $\begin{array}{l}P \mathrm{a}, \mathrm{O}_{2} \\
P \mathrm{~A}-\mathrm{a}, \mathrm{O}_{2}\end{array}$ & $\begin{array}{l}\mathrm{mmHg} \\
\mathrm{mmHg}\end{array}$ & $\begin{array}{l}65 \pm 1 \\
31 \pm 2\end{array}$ & $\begin{array}{l}71 \pm 2 \\
29 \pm 2\end{array}$ & $\begin{array}{c}6 \pm 1^{+} \\
-2 \pm 2\end{array}$ & \\
\hline
\end{tabular}

+: differences significant at $\mathrm{p}<0.0005$, and $95 \%$ confidence intervals not overlapping zero; $\Delta$ Postop-Preop: difference in postoperative minus corresponding preoperative value expressed in absolute units (or in \%) of preoperative value; FRC: functional residual capacity; FVC: forced vital capacity; FEV1: forced expiratory volume in one second; IVC: inspiratory vital capacity; TLC: total lung capacity; RV: residual volume; $D \mathrm{~L}, \mathrm{CO}$ : carbon monoxide diffusing capacity of the lung; $P_{\mathrm{a}, \mathrm{CO}_{2}}$ : arterial carbon dioxide tension; $\mathrm{Pa}_{\mathrm{a}} \mathrm{O}_{2}$ : arterial oxygen tension; $P \mathrm{~A}-\mathrm{a}, \mathrm{O}_{2}$ : alveolar-arterial pressure difference for oxygen. $(0.133 \mathrm{kPa}=1 \mathrm{mmHg}$.) 
Table 2. - Exercise performance (mean values \pm SEM)

\begin{tabular}{|c|c|c|c|c|c|}
\hline \multirow{2}{*}{$\overline{W \max }$} & & Before surgery & After surgery & $\Delta$ Postop-Preop & $\Delta$ Postop-Preop $\%$ \\
\hline & W & $34.3 \pm 2.0$ & $48.9 \pm 2.4$ & $14.6 \pm 2.1^{+}$ & $56 \pm 11^{+}$ \\
\hline \multirow[t]{3}{*}{$V^{\prime} \mathrm{O}_{2}, \max$} & $\mathrm{mL} \cdot \mathrm{kg}^{-1} \cdot \mathrm{min}^{-1}$ & $10.0 \pm 0.4$ & $12.8 \pm 0.3$ & $2.8 \pm 0.3^{+}$ & $31 \pm 4+$ \\
\hline & $\mathrm{mL} \cdot \mathrm{min}^{-1}$ & $636 \pm 27$ & $803 \pm 30$ & $166 \pm 20^{+}$ & \\
\hline & $\%$ pred max & $36 \pm 2$ & $45 \pm 3$ & $9 \pm 1^{+}$ & \\
\hline$\Delta V^{\prime} \mathrm{O}_{2} / \Delta W$ & $\mathrm{~mL} \cdot \min ^{-1} \cdot \mathrm{W}^{-1}$ & $8.9 \pm 0.4$ & $9.6 \pm 0.3$ & $0.9 \pm 0.7$ & \\
\hline$V^{\prime} \mathrm{CO}, \max$ & $\mathrm{mL} \cdot \mathrm{min}^{-1}$ & $587 \pm 30$ & $821 \pm 34$ & $234 \pm 24+$ & $47 \pm 6^{+}$ \\
\hline RQmax & & $0.91 \pm 0.01$ & $1.02 \pm 0.01$ & $0.11 \pm 0.02+$ & \\
\hline$f \operatorname{Rmax}$ & breaths $\cdot \min ^{-1}$ & $29.6 \pm 1.2$ & $28.5 \pm 0.9$ & $-0.9 \pm 1.2$ & \\
\hline$V T, \max$ & $\mathrm{L}$ & $1.03 \pm 0.05$ & $1.38 \pm 0.07$ & $0.35 \pm 0.05+$ & $39 \pm 5^{+}$ \\
\hline$V \mathrm{~T}, \max / \mathrm{IVC}$ & $\%$ & $28 \pm 1$ & $37 \pm 1$ & $9 \pm 1+$ & $36 \pm 6^{+}$ \\
\hline$V^{\prime}$ E,max & $\mathrm{L} \cdot \mathrm{min}^{-1}$ & $29.5 \pm 1.5$ & $38.6 \pm 1.8$ & $9.2 \pm 1.2^{+}$ & $35 \pm 5^{+}$ \\
\hline Breathing & $\mathrm{L} \cdot \mathrm{min}^{-1}$ & $1.1 \pm 1.1$ & $8.4 \pm 2.6$ & $7.3 \pm 2.4^{+}$ & \\
\hline reserve & $\%$ & $1 \pm 4$ & $11 \pm 4$ & $9 \pm 3+$ & \\
\hline$V^{\prime} \mathrm{E}, \max / V^{\prime} \mathrm{O}_{2}, \max$ & & $46.3 \pm 1.1$ & $48.1 \pm 1.3$ & $1.9 \pm 1.1$ & $-5 \pm 2$ \\
\hline$V^{\prime} \mathrm{E}, \max / V^{\prime} \mathrm{CO}_{2}, \mathrm{ma}$ & & $51.3 \pm 1.3$ & $47.3 \pm 1.2$ & $-4.0 \pm 1.4^{+}$ & $-7 \pm 3^{+}$ \\
\hline$V \mathrm{D}, \max / V \mathrm{~T}, \max$ & $\%$ & $45 \pm 1$ & $40 \pm 1$ & $-5 \pm 2+$ & \\
\hline HRmax & beats $\cdot \min ^{-1}$ & $119 \pm 3$ & $122 \pm 3$ & $3 \pm 2$ & \\
\hline HR reserve & beats. $\min ^{-1}$ & $33 \pm 3$ & $30 \pm 3$ & $-3 \pm 2$ & \\
\hline$V^{\prime} \mathrm{O}_{2}, \max / \mathrm{HR} \max$ & $\mathrm{mL} \cdot$ beat & $5.45 \pm 0.25$ & $6.70 \pm 0.28$ & $1.25 \pm 0.20^{+}$ & \\
\hline $\mathrm{pH}$ & & $7.36 \pm 0.01$ & $7.36 \pm 0.01$ & $-0.00 \pm 0.01$ & \\
\hline $\mathrm{Pa}_{\mathrm{a}, \mathrm{CO}_{2}}$ & $\mathrm{mmHg}$ & $41 \pm 1$ & $37 \pm 1$ & $-4 \pm 1+$ & \\
\hline $\mathrm{Pa}_{\mathrm{a}} \mathrm{O}_{2}$ & $\mathrm{mmHg}$ & $57 \pm 2$ & $60 \pm 2$ & $2 \pm 1$ & \\
\hline$P A-a, \mathrm{O}_{2}$ & $\mathrm{mmHg}$ & $39 \pm 2$ & $44 \pm 3$ & $5 \pm 3$ & \\
\hline 6 min walk & $\min$ & $279 \pm 14$ & $366 \pm 12$ & $87 \pm 11^{+}$ & $52 \pm 16^{+}$ \\
\hline
\end{tabular}

Values were taken at maximal oxygen uptake $\left(V^{\prime} \mathrm{O}_{2}, \max \right)$ with the exception of external work efficiency $\left(\Delta V^{\prime} \mathrm{O}_{2} / \Delta W\right)$. +: differences significant at $\mathrm{p}<0.0005$, and $95 \%$ confidence intervals not overlapping zero. $\Delta$ Postop-Preop: difference in postoperative minus corresponding preoperative value expressed in absolute units (or in $\%$ ) of preoperative value. $W$ max: maximal work rate; $V^{\prime} \mathrm{CO}_{2}$,max: maximal carbon dioxide production; $\mathrm{RQmax}$ : maximal respiratory exchange ratio; $f \mathrm{R}$ : respiratory frequency; $V \mathrm{~T}$,max: maximal tidal volume; $V^{\prime} \mathrm{E}$,max: maximal minute ventilation; $V^{\prime} \mathrm{O}_{2}$, max: maximal oxygen consumption; $V \mathrm{D}$,max: maximal dead space; HR: heart rate. For further definitions see legend of table $1 .(1 \mathrm{mmHg}=0.133 \mathrm{kPa})$.

$P$ A-a, $\mathrm{O}_{2}$ from rest to exercise was higher 3 months after LVRS than before surgery $(1.84 \pm 0.31 \mathrm{kPa}(14.8 \pm 2.3 \mathrm{~mm}$ $\mathrm{Hg})$ versus $1.04 \pm 0.17 \mathrm{kPa}(7.8 \pm 1.3 \mathrm{mmHg}) ; \mathrm{p}<0.05)$. Before surgery $\mathrm{Pa}_{\mathrm{a}} \mathrm{CO}_{2}$ increased by $9 \%$ from a resting value of $4.30 \pm 0.13 \mathrm{kPa}(38 \pm 1 \mathrm{mmHg})$ to $5.45 \pm 0.13 \mathrm{kPa}(41 \pm 1$ $\mathrm{mmHg})$ at maximal exercise $(\mathrm{p}<0.01)$. After LVRS there was no such exercise-induced increase in $\mathrm{Pa}_{\mathrm{a}} \mathrm{CO}_{2}$ from rest to maximal exercise $\left(P \mathrm{a}, \mathrm{CO}_{2}\right.$ at rest was $4.66 \pm 0.13 \mathrm{kPa}(35 \pm$ $1 \mathrm{mmHg})$; at maximal exercise $4.92 \pm 0.13 \mathrm{kPa}(37 \pm 1 \mathrm{~mm}$ $\mathrm{Hg}$, $\mathrm{p}=0.15$ ) (tables 1 and 2).

To evaluate whether certain baseline characteristics of pulmonary function or exercise performance would assist in the selection of candidates for LVRS, we determined the median gain in $V^{\prime} \mathrm{O}_{2}$, max which was $2.70 \mathrm{~mL} \cdot \mathrm{kg}^{-1} \cdot \mathrm{min}^{-1}$. This number was rounded to the nearest integer (i.e. 3 $\left.\mathrm{mL} \cdot \mathrm{kg}^{-1} \cdot \mathrm{min}^{-1}\right)$ and the patients were than divided into two groups according to whether their postoperative gain in $V$ $\mathrm{O}_{2}$, max was $>3 \mathrm{~mL} \cdot \mathrm{kg}^{-1} \cdot \mathrm{min}^{-1}$ (favourable responders, $\mathrm{n}=19$ ) or $ð 3 \mathrm{~mL} \cdot \mathrm{kg}^{-1} \cdot \mathrm{min}^{-1}$ (modest responders $\mathrm{n}=21$ ). With the exception of a slightly lower $V^{\prime} \mathrm{O}_{2}, \max , V^{\prime} \mathrm{E}$,max and forced vital capacity (FVC) in the group with greater increase in $V^{\prime} \mathrm{O}_{2}$, max $\left(>3 \mathrm{~mL} \cdot \mathrm{kg}^{-1} \cdot \mathrm{min}^{-1}\right)$, the differences were statistically not significant (table 3 ). Furthermore, there was a loose negative correlation between preoperative $V^{\prime} \mathrm{O}_{2}$, max, $V$ T,max and $V^{\prime}$ E,max with the postoperative gain in $V^{\prime} \mathrm{O}_{2}$, max (table 4), while the correlations of changes in $V^{\prime} \mathrm{O}_{2}$, max with preoperative measures of airflow obstruction and hyperinflation (FEV1 and RV/TLC) were statistically not significant (table 4). On the other hand, the changes in $V^{\prime} \mathrm{O}_{2}$, max were correlated with the changes in $V^{\prime} \mathrm{E}, \max , V \mathrm{~T}$, max and FEV1 (table 4).

\section{Discussion}

We prospectively investigated the effects of bilateral video-assisted thoracoscopic LVRS on dyspnoea, pulmonary function and exercise performance in 40 patients with severe pulmonary emphysema. We found significant improvements in dyspnoea, airflow obstruction and hyperinflation. Furthermore, the 6 min walking distance and the maximal performance during bicycle spiroergometry im-proved. This was related to changes in respiratory mech-anics and breathing pattern. Our findings corroborate the results of earlier studies that included a detailed analysis of exercise performance after LVRS by median sterno-tomy [13] and unilateral video-assisted thoracoscopy [14]. We were able to extend the observations to a larger group of patients and to the study of the effects of bilateral LVRS by video-assisted thoracoscopy.

\section{Dyspnoea and pulmonary function at rest}

According to our selection criteria for LVRS, the patients preoperatively suffered from severe dyspnoea related to pronounced airflow obstruction and hyperinflation (table 1). The reduction of breathlessness during daily activities as reflected in a decrease in the mean MRC dyspnoea score of 2 points (table 1) and the degree of improvement in pulmonary function (mean increase in FEV 1 of $55 \%$, mean decrease in TLC of $8 \%$, table 1) are similar to corresponding changes in dyspnoea and pulmonary function achieved by bilateral LVRS in other studies involving patients 

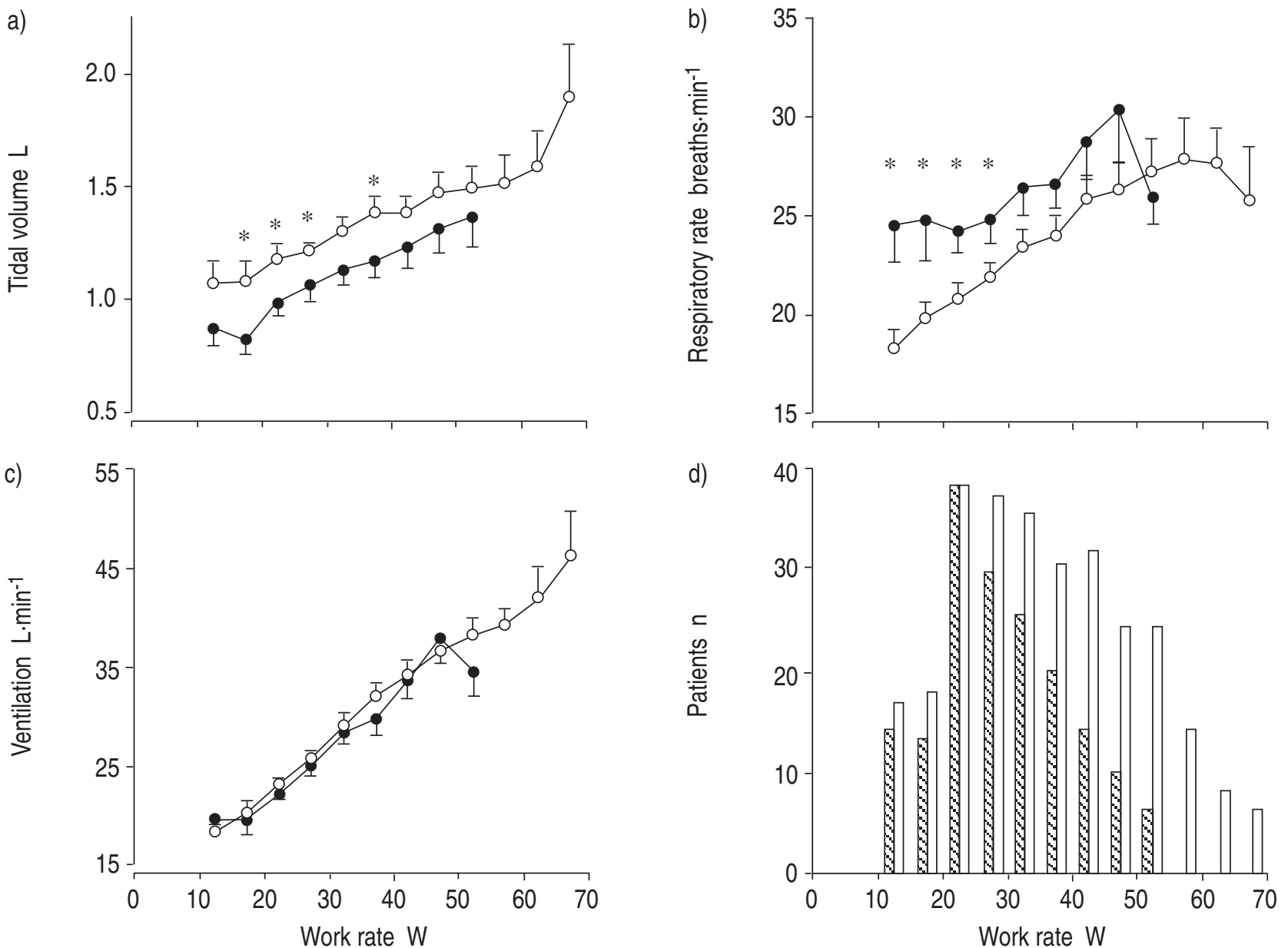

Fig. 1. - For each individual, parameters of exercise performance for a) tidal volume, b) respiratory rate, and c) ventilation, were averaged over successive 5-W work rate ranges starting with the lowest range (which was between 10-15 and 20-25 W) up to maximal work rate. The plots represent group mean values $( \pm$ SEM) plotted against work rate ranges for tests before $(\bullet)$ and after $(O)$ lung volume reduction surgery. Circles are located at the mean work rate of the respective range (e.g. at $12.5 \mathrm{~W}$ for the range $10-15 \mathrm{~W}$ ). Work rate ranges that were attained by fewer than six patients were omitted. Therefore, and due to differences among individuals in the lowest as well as in the maximal work rate, the number of patients included into means for successive work rate ranges varies $(\mathrm{d}) . *$ : $<<0.05$, significant differences between preoperative and postoperative means.

with a comparable preoperative pulmonary impairment [3]. For example, the mean changes in FEV1 and TLC were $+51 \%$ and $-14 \%$, respectively, in 101 patients, 6 months after bilateral LVRS by median sternotomy [3]. In two other studies that included a detailed analysis of exercise performance, FEV1 and TLC changed by $35 \%$ and $7 \%$, respectively, three months after bilateral LVRS by median sternotomy [13], and FEV1 increased by 30\% 3-6 months after LVRS by unilateral video-assisted thoracoscopy [14]. The comparisons of our data with those from the cited studies suggests that the gain in pulmonary function achieved after bilateral LVRS by video-assisted thoracoscopy is similar to that after bilateral LVRS by median sternotomy [13], but may exceed the improvements obtained after unilateral LVRS by video-assisted thoracoscopy [14].

\section{Maximal exercise performance}

The increase in the 6 min walking distance of $52 \%$ from the preoperative value indicated an improvement in general exercise performance after LVRS, similar to the increase of $28-59 \%$ in this test found by other investigators [7, 21]. Accordingly, maximal performance during incremental bicycle exercise was significantly improved as well, as evidenced by an increase in maximal workload of $56 \%$ and in the $V^{\prime} \mathrm{O}_{2}$, max of $31 \%$ (table 2). Corresponding values three months after LVRS by median sternotomy were $46 \%(\Delta W \max )$ and $25 \%\left(\Delta V^{\prime} \mathrm{O}_{2}, \max \right)[13]$. For the study investigating the effects of unilateral video-assisted thoracoscopic LVRS [14] the relative changes in these variables were not reported, but the absolute values of $W$ max increased from 37 to $52 \mathrm{~W}$, and $V^{\prime} \mathrm{O}_{2}$, max increased from 9.7 to $11.8 \mathrm{~mL} \cdot \mathrm{kg}^{-1} \cdot \mathrm{min}^{-1}$ [14]. These changes are of a similar order of magnitude to those in the current study (table 2). The relatively greater improvement in $W \max (56 \%)$ than in $V^{\prime} \mathrm{O}_{2}$,max $(31 \%)$ was not related to a increase in external work efficiency since $\Delta V^{\prime} \mathrm{O}_{2} / \Delta W$ remained unchanged (table 2). Potential explanations for this effect are a greater motivation to perform exercise, an increase in cardiovascular fitness, as suggested by an unchanged heart rate at higher workload and a higher oxygen pulse (table 2), and increased muscle strength. In contrast to the protocol reported by other centres [14], these 
Table 3. - Comparison of baseline characteristics of pulmonary function and exercise performance as a function of postoperative gain in maximal oxygen uptake

\begin{tabular}{|c|c|c|c|}
\hline \multicolumn{2}{|c|}{ Baseline performance } & $\begin{array}{c}\Delta V^{\prime} \mathrm{O}_{2}, \max \\
\text { ð3 } \mathrm{mL} \cdot \mathrm{kg}^{-1} \cdot \mathrm{min}^{-1} \\
\mathrm{n}=21\end{array}$ & $\begin{array}{c}\Delta V^{\prime} \mathrm{O}_{2}, \max \\
>3 \mathrm{~mL} \cdot \mathrm{kg}^{-1} \cdot \mathrm{min}^{-1} \\
\mathrm{n}=19\end{array}$ \\
\hline$W \max$ & $\begin{array}{l}\mathrm{W} \\
\% \text { pred }\end{array}$ & $\begin{array}{c}35.6 \pm 2.9 \\
26 \pm 2\end{array}$ & $\begin{array}{c}32.9 \pm 2.6 \\
27 \pm 3\end{array}$ \\
\hline$V^{\prime} \mathrm{O}_{2}$,max & $\mathrm{mL} \cdot \mathrm{kg}^{-1} \cdot \mathrm{min}^{-1}$ & $10.8 \pm 0.5$ & $9.1 \pm 0.4 *$ \\
\hline$f \mathrm{Rmax}$ & breaths $\cdot \mathrm{min}^{-1}$ & $30.7 \pm 1.5$ & $28.5 \pm 1.8$ \\
\hline$V \mathrm{~T}, \max$ & $\mathrm{L}$ & $1.10 \pm 0.1$ & $0.95 \pm 0.1$ \\
\hline$V^{\prime} \mathrm{E}, \max$ & $\mathrm{L} \cdot \mathrm{min}^{-1}$ & $32.7 \pm 2.3$ & $26.2 \pm 1.8^{*}$ \\
\hline $\begin{array}{l}\text { Breathing } \\
\text { reserve }\end{array}$ & $\begin{array}{l}\mathrm{L} \cdot \mathrm{min}^{-1} \\
\%\end{array}$ & $\begin{array}{c}0.0 \pm 1.5 \\
-2 \pm 5\end{array}$ & $\begin{array}{c}2.3 \pm 1.7 \\
5 \pm 6\end{array}$ \\
\hline$H R \max$ & beats. $\min ^{-1}$ & $120 \pm 4$ & $118 \pm 3$ \\
\hline HR reserve & beats. $\min ^{-1}$ & $32 \pm 5$ & $34 \pm 4$ \\
\hline FVC & $\%$ pred & $76 \pm 3$ & $64 \pm 3 *$ \\
\hline FEV 1 & $\%$ pred & $31 \pm 2$ & $27 \pm 1$ \\
\hline TLC & $\%$ pred & $143 \pm 3$ & $134 \pm 4$ \\
\hline \multicolumn{2}{|l|}{$\mathrm{RV} / \mathrm{TLC}$} & $0.61 \pm 0.0$ & $0.66 \pm 0.0$ \\
\hline
\end{tabular}

*: differences significant at $\mathrm{p}<0.05$. For definitions see legends to tables 1 and 2.

results were achieved without systematic rehabilitation. However, it is conceivable that systematic pulmonary rehabilitation might further improve the patient's level of exercise performance after LVRS.

The analysis of ventilatory mechanics, breathing patterns and gas exchanges provided insight into the physiological mechanisms by which the improvements in exercise capacity were achieved.

\section{Ventilatory mechanics and breathing patterns}

The decreased or absent breathing reserve at maximal exercise suggests that exercise limitation in our patients was primarily related to a decreased ventilatory capacity, which is consistent with the known effects of severe chronic obstructive lung disease [22]. After surgery, when airflow obstruction and hyperinflation were improved (table 1), $V^{\prime}$ E,max increased significantly. The correlation of the individual increases in $V^{\prime} \mathrm{E}$, max and $V^{\prime} \mathrm{O}_{2}$, max with the increases in FEV1 $(\mathrm{R}=0.72, \mathrm{p}<0.05$, and $\mathrm{R}=0.53, \mathrm{p}<0.05$, respectively) and with the decreases in $\mathrm{RV} / \mathrm{TLC}(\mathrm{R}=-0.60$, $\mathrm{p}<0.05$, and $\mathrm{R}=-0.49, \mathrm{p}<0.05$, respectively) support the hypothesis that the improvements in airflow obstruction and hyperinflation are important factors contributing to increased exercise performance after surgery.

We found that the augmentation in $V^{\prime}$ E,max after LVRS was achieved by an increase in $V \mathrm{~T}$ while maximal breathing frequency remained unchanged (table 2). In addition, ventilation at various levels of isowatt exercise was similar before and after surgery, but after LVRS the corresponding levels of $V^{\prime} \mathrm{E}$ were achieved by higher $V_{\mathrm{T}}$ and lower respiratory frequency $(f R)$ than preoperatively (fig. 1). Therefore, the rapid shallow breathing patterns which are characteristic for patients with severe chronic obstructive pulmonary disease (COPD) during exercise [13, 14, 23] were partially improved by LVRS. These observations corroborate the findings of BendiTT et al. [13] in a group of emphysema patients with a similar degree of impairment prior to and improvements after LVRS.

In normal subjects, the increase in $V^{\prime} E$ during exercise is initially achieved by increasing both $V \mathrm{~T}$ and $f \mathrm{R}$. At higher work rates, however, when $V \mathrm{~T}$ has reached about $50-60 \%$ of vital capacity, further increases in $V^{\prime} \mathrm{E}$ are predominately due to increases in $f \mathrm{R}$ [24]. In the current study, the $V \mathrm{~T} / \mathrm{IVC}$ ratio at maximal exercise was only $28 \%$ before surgery but rose slightly to more normal values (37\%) after LVRS (table 2). This is consistent with partial relief of severe airflow obstruction which may have been associated with a reduction in expiratory flow limitation and dynamic hyperinflation. Our data do not allow differentiation between various factors that may have contributed to the changes in breathing patterns and the increase in $V^{\prime} \mathrm{E}$, max such as improvements in bronchial obstruction related to restoration of elastic recoil [25], reduction of dynamic hyperinflation [26], and increases in inspiratory and expiratory muscle performance [27].

Table 4. - Correlation of preoperative baseline values and changes in various parameters with improvement in maximal oxygen uptake $\left(V^{\prime} \mathrm{O}_{2}\right.$,max $)$

\begin{tabular}{|c|c|c|c|c|c|}
\hline & & \multicolumn{2}{|c|}{$\begin{array}{l}\text { Correlation of } \Delta V^{\prime} \mathrm{O}_{2} \text {,max } \\
\text { with preoperative values }\end{array}$} & \multicolumn{2}{|c|}{$\begin{array}{l}\text { Correlation of } \Delta V^{\prime} \mathrm{O}_{2}, \max \\
\text { with changes* }\end{array}$} \\
\hline & & $\mathrm{R}$ & $\overline{p \text {-value }}$ & $\mathrm{R}$ & $\overline{p \text {-value }}$ \\
\hline$\overline{V^{\prime} \mathrm{O}_{2}, \max \mathrm{m}}$ & $\mathrm{mL} \cdot \mathrm{kg}^{-1} \cdot \mathrm{min}^{-1}$ & -0.60 & $<0.001$ & 1 & \\
\hline & $\%$ pred & -0.28 & NS & 0.34 & 0.032 \\
\hline$f \mathrm{R}$ & breaths $\cdot \min ^{-1}$ & -0.21 & NS & 0.10 & NS \\
\hline$V_{\mathrm{T}}$ & $\mathrm{L}$ & -0.34 & 0.037 & 0.57 & $<0.001$ \\
\hline$V^{\prime} \mathrm{E}$ & $\mathrm{L} \cdot \mathrm{min}^{-1}$ & -0.41 & $<0.001$ & 0.76 & $<0.001$ \\
\hline FEV1 & $\%$ pred & -0.21 & 0.026 & 0.53 & $<0.001$ \\
\hline RV/LC & & 0.29 & NS & -0.49 & 0.001 \\
\hline
\end{tabular}

*: changes were calculated as the difference between postoperative-preoperative value in per cent of the preoperative value of corresponding variables. $\mathrm{R}$ : coefficient of variation versus $V^{\prime} \mathrm{O}_{2}$, max $\left(\mathrm{mL} \cdot \mathrm{kg}^{-1}\right.$. $\left.\min ^{-1}\right)$. For definitions see legends to tables 1 and 2 . 


\section{Gas exchange}

The impairment of gas exchange at rest was reflected in a low diffusing capacity (preoperative DL,CO of $44 \%$ pred, table 1) as has previously been described for severe emphysema [28] and observed in candidates for LVRS in other centres [25, 29]. We did not observe a significant change in diffusing capacity after LVRS, which is consistent with data by MARTinez et al. [29] and ScIURBA et al. [25]. We believe that this is due to the fact that no significant amount of functional lung tissue is removed. Alternatively, the loss of lung parenchyma related to resection is offset by recruiting compressed parts of the remaining lung, thereby enhancing gas exchange capacity. Gelb et al. [30] even described a rise in DL,CO from $9 \%$ pred preoperatively to $38 \%$ pred after LVRS, and, in a more recent paper, from $18 \%$ to $43 \%$ pred [31]. These differences might be related to distinct morphologies of emphysema [19] or to differences in the amount and selection of resected target areas.

As a group, our candidates for LVRS, for whom hypercapnia $\left(\mathrm{Pa}, \mathrm{CO}_{2}>7.3 \mathrm{kPa}(55 \mathrm{mmHg})\right)$ was an exclusion criterion [4], had only mild hypoxaemia at rest, and only six of them required long-term oxygen therapy according to standard criteria [20]. Three months after LVRS, we found a mild increase in resting $\mathrm{Pa}, \mathrm{O}_{2}$ associated with a decrease in $P \mathrm{a}, \mathrm{CO}_{2}$, the $P \mathrm{~A}-\mathrm{a}, \mathrm{O}_{2}$ remaining unaltered (table 1). Two of the six patients who were on long-term oxygen therapy preoperatively no longer fulfilled the criteria for this treatment. Similar trends of changes in blood gases were reported by others $[3,13]$.

Before surgery, $\mathrm{Pa}, \mathrm{O}_{2}$ decreased during exercise in comparison with resting values. After LVRS, the exerciseinduced decrease in $\mathrm{Pa}, \mathrm{O}_{2}$ persisted and the difference in the $P \mathrm{~A}-\mathrm{a}, \mathrm{O}_{2}$ between rest and exercise even increased. However, we did not measure the blood gases at comparable levels of exercise pre- and postoperatively (i.e. before surgery (table 2)). The capacity to maintain a relatively low $P \mathrm{a}, \mathrm{CO}_{2}$ at a level of maximal exercise which exceeded that before surgery was related to a greater $V^{\prime} \mathrm{CO}_{2}$, max which increased by $47 \%$ (table 2). This was achieved by the combined effects of an augmentation in $V^{\prime} \mathrm{E}, \max$ (by 35\%) and a reduction in $V \mathrm{D}, \max / V \mathrm{~T}$, max (by $5 \%$ ), the latter being less important since the ventilatory equivalent for $\mathrm{CO}_{2}$ decreased only slightly (by 7\%, table 2). In other words, while dead space ventilation during maximal exercise was reduced to some degree after LVRS, the gain in $V^{\prime} \mathrm{CO}_{2}$ was mainly related to improvements in ventilatory mechanics which provided the capacity to take deeper breaths at an unchanged $f \mathrm{R}$ during maximal exercise. These findings corroborate data reported by others $[13,14]$.

\section{Correlation of preoperative pulmonary function and exercise performance with outcome after LVRS}

The only baseline characteristics that differentiated patients with a $>3 \mathrm{~mL} \cdot \mathrm{kg}^{-1} \cdot \mathrm{min}^{-1}$ increase in $V^{\prime} \mathrm{O}_{2}$, max from those with an increase in $V^{\prime} \mathrm{O}_{2}$, $\max$ of $\partial 3 \mathrm{~mL} \cdot \mathrm{kg}^{-1} \cdot \mathrm{min}^{-1}$ were $V^{\prime} \mathrm{O}_{2}$,max and $V^{\prime} \mathrm{E}$,max. As a group, the patients with greater improvements in $V^{\prime} \mathrm{O}_{2}$, max had lower baseline $V^{\prime} \mathrm{O}_{2}$, max and $V^{\prime} \mathrm{E}$,max than the remainder of the patients (table 3 ). However, there was a large overlap among the groups and only $36 \%$ and $17 \%$ of the variability of the postopera- tive gain in $V^{\prime} \mathrm{O}_{2}$,max could be explained by variation in baseline $V^{\prime} \mathrm{O}_{2}$, max and $V^{\prime} \mathrm{E}$,max, respectively (table 4). The relatively weak correlations between baseline measures of airflow obstruction (FEV1) and hyperinflation (RV/TLC) with changes in $V^{\prime} \mathrm{O}_{2}$, max (table 4) may be related in part to selection bias, since only patients with severe airflow obstruction and hyperinflation were accepted for surgery. Thus, within the candidates for LVRS that fulfilled our selection criteria, neither baseline pulmonary function tests nor characteristics of preoperative exercise performance reliably predicted functional outcome after surgery. Nevertheless, our data suggest, that even a very poor preoperative exercise performance does not preclude significant improvements after LVRS.

\section{Conclusions}

Our study confirms earlier reports of significant improvements in pulmonary function and exercise performance achieved by lung volume reduction surgery in selected patients with severe pulmonary emphysema. Bilateral videoassisted thoracoscopic lung volume reduction surgery seems to provide comparable improvements as bilateral lung volume reduction surgery by median sternotomy. Based on analysis of breathing patterns and gas exchange, the gain in exercise performance after lung volume reduction surgery is mediated primarily by improvements in respiratory mechanics.

\section{References}

1. Brantigan OC, Mueller EA, Kress MB. A surgical approach to pulmonary emphysema. Am Surgeon 1957; 23: 789-804.

2. Cooper JD, Trulock EP, Triantafillou AN, et al. Bilateral pneumectomy (volume reduction) for chronic obstructive pulmonary disease. J Thorac Cardiovasc Surg 1995; 109: 106-119.

3. Cooper JD, Patterson GA, Sundaresan RS, et al. Results of 150 consecutive bilateral lung volume reduction procedures in patients with severe emphysema. $J$ Thorac Cardiovasc Surg 1996; 112: 1319-1330.

4. Bingisser R, Zollinger A, Hauser M, Bloch KE, Russi $\mathrm{EW}$, Weder W. Bilateral volume reduction surgery for diffuse pulmonary emphysema by video-assisted thoracoscopy. J Thorac Cardiovasc Surg 1996; 112: 875-882.

5. Stammberger U, Thurnheer R, Bloch KE, et al. Thoracoscopic bilateral lung volume reduction for diffuse pulmonary emphysema. Eur J Cardiothorac Surg 1997; 11: 1005-1010.

6. Demertzis S, Schäfers HJ, Wagner TOF, Hausen B, Fabel $\mathrm{H}$, Borst HG. Bilaterale Lungenvolumenreduktion bei schwerem Emphysem. Dtsch Med Wochenschr 1996; 121: 427-433.

7. Kotloff RM, Tino G, Bavaria JE, et al. Bilateral lung volume reduction surgery for advanced emphysema - a comparison of median sternotomy and thoracoscopic approaches. Chest 1996; 110: 1399-1406.

8. Stamatis G, Teschler H, Fechner S, et al. Bilaterale Lungenvolumenreduktion bei Patienten mit schwerem Lungenemphysem. Pneumologie 1996; 50: 448-452.

9. McKenna RJ Jr, Brenner M, Gelb AF, et al. A randomized, prospective trial of stapled lung reduction versus 
laser bullectomy for diffuse emphysema. $J$ Thorac Cardiovasc Surg 1996; 111: 317-322.

10. Keenan RJ, Landreneau RJ, Sciurba FC, et al. Unilateral thoracoscopic surgical approach for diffuse emphysema. J Thorac Cardiovasc Surg 1996; 111: 308-316.

11. Naunheim KS, Keller CA, Krucylak PE, Singh A, Ruppel $\mathrm{G}$, Osterloh J. Unilateral video-assisted thoracic surgical lung reduction. Ann Thorac Surg 1996; 61: 1092-1098.

12. Gallagher CG. Exercise limitation and clinical exercise testing in chronic obstructive pulmonary disease. Clin Chest Med 1994; 15: 305-326.

13. Benditt JO, Lewis S, Wood DE, Klima L, Albert RK. Lung volume reduction surgery improves maximal $\mathrm{O}_{2}$ consumption, maximal minute ventilation, $\mathrm{O}_{2}$ pulse, and dead space-to-tidal volume ratio during leg cycle ergometry. Am J Respir Crit Care Med 1997; 156: 561-566.

14. Keller CA, Ruppel G, Hibbet A, Osterloh J, Naunheim KS. Thoracoscopic lung volume reduction surgery reduces dyspnea and improves exercise capacity in patients with emphysema. Am J Respir Crit Care Med 1997; 156: 60-67.

15. Russi EW, Stammberger U, Weder W. Lung volume reduction surgery for emphysema. Eur Respir J 1997; 19: 208-218.

16. Thurnheer R, Muntwyler J, Stammberger U, et al. Coronary artery disease in patients undergoing lung volume reduction surgery for emphysema. Chest 1997; 112: 122128.

17. American Thoracic Society. Surveillance for respiratory hazards in the occupational setting. Am Rev Respir Dis 1982; 126: 952-956.

18. ECCS working party. Standardization of lung function tests. Bull Europ Physiopath Respir 1983; 19: 7-92.

19. Weder W, Thurnheer R, Stammberger U, Bürge M, Russi EW, Bloch KE. Radiological emphysema morphology is associated with outcome after surgical lung volume reduction. Ann Thorac Surg 1997; 64: 313-320.

20. American Thoracic Society. Standards for the diagnosis and care of patients with chronic obstructive pulmonary disease. Am J Respir Crit Care Med 1995; 152: S77S120.

21. Miller JI Jr, Lee RB, Mansour KA. Lung volume reduc- tion surgery: lessons learned. Ann Thorac Surg 1996; 61: 1464-1469.

22. Montes de Oca M, Rassulo J, Celli BR. Respiratory muscle and cardiopulmonary function during exercise in very severe COPD. Am J Respir Crit Care Med 1996; 154: 1284-1289.

23. O'Donnell DE, Webb KA, Bertley JC, Chau LKL, Conlan AA. Mechanisms of relief of exertional breathlessness following unilateral bullectomy and lung volume reduction surgery in emphysema. Chest 1996; 110: 18-27.

24. Jones NL, Makrides L, Hitchcock C, Chypchar T, McCartney N. Normal standards for an incremental progressive cycle ergometer test. Am Rev Respir Dis 1985; 131: 700708.

25. Sciurba FC, Rogers RM, Keenan RJ, et al. Improvement in pulmonary function and elastic recoil after lung-reduction surgery for diffuse emphysema. N Engl J Med 1996; 334: 1095-1099.

26. Tschernko EM, Wisser W, Wanke T, et al. Changes in ventilatory mechanics and diaphragmatic function after lung volume reduction surgery in patients with COPD. Thorax 1997; 52: 545-550.

27. Teschler H, Stamatis G, El-Raouf Farhat AA, Meyer FJ, Costabel U, Konietzko N. Effect of surgical lung volume reduction on respiratory muscle function in pulmonary emphysema. Eur Respir J 1996; 9: 1779-1784.

28. Owens GR, Rogers RM, Pennock BE, Levin D. The diffusing capacity as a predictor of arterial oxygen desaturation during exercise in patients with chronic obstructive pulmonary disease. N Engl J Med 1984; 310: 1218-1221.

29. Martinez FJ, Montes de Oca M, Whyte RI, Stetz J, Gay $\mathrm{SE}$, Celli BR. Lung-volume reduction improves dyspnea, dynamic hyperinflation, and respiratory muscle function. Am J Respir Crit Care Med 1997; 155: 1984-1990.

30. Gelb AF, Zamel N, McKenna RJ Jr, Brenner M. Mechanism of short-term improvement in lung function after emphysema resection. Am J Respir Crit Care Med 1996; 154: 945-951.

31. Gelb AF, Brenner M, McKenna RJ Jr, Zamel N, Fischel RJ, Epstein JD. Lung function 12 months following emphysema reduction. Chest 1996; 110: 1407-1415. 